\title{
EMPREENDEDORISMO E GERENCIAMENTO: \\ processos distintos, porém complementares
}

Louis Jacques Filion

\section{INTRODUÇÃO}

A necessidade de desenvolver programas, cursos e atividades de treinamento sobre empreendedorismo parece crescer a cada ano em diversos países. As questões freqüentemente levantadas por quem desenvolve esses programas são: Qual é a diferença entre gerenciamento e empreendedorismo? O que um programa de formação empreendedora deveria conter? Quais cursos deveriam ser oferecidos? Como esses cursos deveriam ser ministrados? Este artigo não pretende responder a todas as questões. O que ele faz é apresentar um certo número de diretrizes desenvolvidas, de modo a atender às necessidades da formação profissional, baseando-se em uma década de experiência tanto em pesquisa sobre empreendedorismo quanto na criação e administração de programas educacionais voltados para empreendedorismo e pequenos negócios em níveis de formação e graduação universitária.

\section{GERENCIAMENTO E EMPREENDEDORISMO: ALGUMAS DIFERENÇAS}

Timmons (1978), Hornaday (1982), Brockhaus e Horwitz (1986) e Hisrich (1986) pesquisaram a literatura sobre as características comumente atribuídas aos empreendedores. Essas características são apresentadas no Quadro 1.

Tais características são encontradas em auto-empregados, proprietários de pequenos negócios e 
empreendedores em geral. Entretanto, outras características comuns a empreendedores bem-sucedidos foram igualmente identificadas (Filion, 1991). Elas estão listadas no Quadro 2.

Wortman e Birkenholz (1991) apresentam uma visão condensada do campo do empreendedorismo. Nossa preocupação não é tanto com as características psicológicas dos empreendedores, mas sim com os aspectos diferenciais de como eles trabalham: em outras palavras, como eles imaginam, projetam e operam seus sistemas de atividades humanas.

Mintzberg (1975), Boyatzis (1982), Kotter (1982) e Hill (1992) examinaram o trabalho dos geren-

\section{Quadro 1 - Características comuns aos empreendedores}

\begin{tabular}{ll} 
- & Apresentam tenacidade \\
\hline - & Possuem capacidade de tolerar ambigüidade e incerteza \\
\hline - & Fazem bom uso de recursos \\
\hline - & Correm riscos moderados \\
\hline - & São imaginativos \\
\hline - & Voltam-se para resultados
\end{tabular}

\section{Quadro 2 - Características de empreendedores bem-sucedidos}

\begin{tabular}{ll|}
\hline - & $\begin{array}{l}\text { Valores e cultura de empreendedorismo adquiridos por meio de contato } \\
\text { com, pelo menos, um modelo empreendedor durante a sua juventude }\end{array}$ \\
\hline - & Experiência em negócios \\
\hline - & Diferenciação \\
\hline - & Intuição \\
\hline - & Envolvimento \\
\hline - & Trabalhadores incansáveis \\
\hline - & Sonhadores realistas (visionários) \\
\hline - & Líderes \\
\hline - & Trabalham em rede com moderação \\
\hline - & Têm o seu próprio sistema de relações com os empregados \\
\hline - & Controladores do comportamento das pessoas ao seu redor \\
\hline - & Aprendizagem dos seus próprios padrões \\
\hline
\end{tabular}

tes. Esses estudos revelam consideráveis diferenças nos métodos operacionais de gerentes e empreendedores, como mostra o Quadro 3.

Os gerentes perseguem os objetivos fazendo uso efetivo e eficiente dos recursos. Eles normalmente trabalham dentro de estruturas previamente definidas por outra pessoa.

As organizações criadas por empreendedores, no entanto, são, na realidade, uma extrapolação de seus mundos subjetivos. O que os empreendedores fazem está intimamente ligado à maneira como interpretam o que está ocorrendo em um setor em particular do meio. Seu conhecimento de um mercado específico ou do desenvolvimento de um novo produto ou de um novo processo fabril irá levá-los a ter uma visão de alguma coisa diferente e a comercializá-la. Definem maneiras de fazer as coisas que refletem o que eles próprios são, e o sucesso deles depende do quanto aquilo que foi definido é adequado e diferente e o quanto isso satisfaz as necessidades variáveis das pessoas. Os empreendedores não apenas definem situações, mas também imaginam visões sobre o que desejam alcançar. Sua tarefa principal parece ser a de imaginar e definir o que querem fazer e, quase sempre, como irão fazê-lo.

De uma maneira geral, o gerenciamento é associado à racionalidade e o empreendedorismo, à intui-

\section{Quadro 3 - Diferenças nos sistemas de atividades de gerentes e empreendedores}

\begin{tabular}{|c|c|}
\hline GERENTES & EMPREENDEDORES \\
\hline $\begin{array}{l}\text { Trabalham com a eficiência e o uso efetivo } \\
\text { dos recursos para atingir metas e objetivos }\end{array}$ & $\begin{array}{l}\text { Estabelecem uma visão e objetivos e identificam os } \\
\text { recursos para torná-los realidade }\end{array}$ \\
\hline - A chave é adaptar-se às mudanças & - A chave é iniciar as mudanças \\
\hline - O padrão de trabalho implica análise racional & - O padrão de trabalho implica imaginação e criatividade \\
\hline - Operam dentro da estrutura de trabalho existente & $\begin{array}{l}\text { - Definem tarefas e funções que criem uma estrutura de } \\
\text { trabalho }\end{array}$ \\
\hline $\begin{array}{l}\text { Trabalho centrado em processos que levam em } \\
\text { consideração o meio em que ele se desenvolve }\end{array}$ & $\begin{array}{l}\text { - Trabalho centrado na criação de processos resul- } \\
\text { tantes de uma visão diferenciada do meio }\end{array}$ \\
\hline
\end{tabular}


ção, embora, em ambos os casos, esses atributos devam ser considerados predominantes, em vez de exclusivos. Atividades empreendedoras requerem estruturas de trabalho sistêmicas que incluem conceitos (Peterson, 1981; Drucker, 1985), ainda que num nível diferente do das atividades gerenciais, e estas últimas requerem elementos de intuição e imaginação. No entanto, as atividades conceituais e as habilidades dos dois grupos são diferentes. Dessa forma, seus requisitos educacionais também deveriam ser diferentes.

\section{FORMAÇÃO \\ EMPREENDEDORA E GERENCIAL}

Essas diferenças básicas entre gerentes e empreendedores exigem fundamentalmente métodos educacionais e de treinamentos diferentes. $\mathrm{Na}$ educação geral, o que normalmente se enfatiza é a aquisição de conhecimento, enquanto, na educação gerencial, é a aquisição de know-how e, na educação empreendedora, a aquisição de autoconhecimento $^{1}$ (Gasse, 1992). O Quadro 4 examina as conseqüências das diferenças listadas no Quadro 3 sobre as abordagens educacionais.
Essa comparação limitada traz dois conceitos complementares: know-how e autoconhecimento. Ambos manifestam-se de formas diferentes em gerentes e empreendedores. Em termos de autoconhecimento, muitos autores insistem na adaptabilidade dos gerentes

\section{Os gerentes}

perseguem os objetivos fazendo

uso efetivo e eficiente dos recursos. Eles normalmente trabalham dentro de estruturas previamente definidas por outra pessoa.

(Archambault, 1992; Hill, 1992), enquanto, para os empreendedores, a palavra-chave é perseverança (Hornaday, 1982; Filion,1991). Quanto a know-how, os gerentes devem usar abordagens racionais, po- rém dentro de uma estrutura de trabalho predefinida. Empreendedores, por outro lado, devem ter uma abordagem imaginativa e definir sua própria estrutura de trabalho. Devem identificar um nicho e, então, ter uma visão de alguma coisa ou algum lugar a ser ocupado no mercado e saber qual é o tipo de organização necessária para tornar isso realidade. Pesquisas sobre sistemas de atividades empreendedoras mostram que o trabalho do empreendedor consiste principalmente em definir contextos e estruturas de trabalho (Filion, 1990).

As seções seguintes examinam alguns aspectos específicos da formação do ensino de empreendedorismo e sugerem abordagens que poderiam ser usadas para dar melhor suporte às particularidades da disciplina.

\section{ASPECTOS ESPECÍFICOS DO ENSINO DO EMPREENDEDORISMO}

Em qualquer programa educacional, o importante não é somente o que se aprende, mas como isso é aprendido (em outras palavras, o padrão de aprendizagem estabelecido). Os participantes de um programa educacional devem sentir-se à

Quadro 4 - Diferenças básicas entre as formações gerencial e empreendedora

\begin{tabular}{|c|c|}
\hline FORMAÇÃO GERENCIAL & FORMAÇÃO EMPREENDEDORA \\
\hline - Baseada em cultura de afiliação & - Baseada em cultura de liderança \\
\hline $\begin{array}{l}\text { - Centrada em trabalho de grupo e comunicação } \\
\text { de grupo }\end{array}$ & - Centrada na progressão individual \\
\hline $\begin{array}{l}\text { - Trabalha no desenvolvimento de ambos os lados } \\
\text { do cérebro, com ênfase no lado esquerdo }\end{array}$ & $\begin{array}{l}\text { Trabalha no desenvolvimento de ambos os lados } \\
\text { do cérebro, com ênfase no lado direito }\end{array}$ \\
\hline $\begin{array}{l}\text { Desenvolve padrões que buscam regras } \\
\text { gerais e abstratas }\end{array}$ & $\begin{array}{l}\text { - Desenvolve padrões que buscam aplicações } \\
\text { específicas e concretas }\end{array}$ \\
\hline $\begin{array}{l}\text { - Baseada no desenvolvimento do autoconhecimento } \\
\text { com ênfase na adaptabilidade }\end{array}$ & $\begin{array}{l}\text { - Baseada no desenvolvimento do autoconhecimento } \\
\text { (conceito de si) com ênfase na perseverança }\end{array}$ \\
\hline $\begin{array}{l}\text { Voltada para a aquisição de know-how em } \\
\text { gerenciamento de recursos e na própria } \\
\text { área de especialização }\end{array}$ & $\begin{array}{l}\text { Voltada para a aquisição de know-how direcionado } \\
\text { para a definição de contextos que levem à ocupação } \\
\text { de um lugar no mercado }\end{array}$ \\
\hline
\end{tabular}


vontade e prontos para desempenhar o novo papel para o qual estão sendo preparados. Um programa de empreendedorismo deve, portanto, concentrar-se mais no desenvolvimento do conceito de si e na aquisição de know-how do que na simples transmissão de conhecimento. O conceito de si a ser desenvolvido deve enfocar a autonomia, a autoconfiança, a perseverança, a determinação, a criatividade, a liderança e a flexibilidade (Timmons, 1978; Hornaday, 1982; Brockhaus e Horwitz, 1986; Hisrich, 1986). O know-how deve focalizar, sobretudo, a definição de situações. Essa, como vimos anteriormente, é a atividade principal dos empreendedores: conhecer e entender mercados, identificar oportunidades de negócios, selecionar objetivos, imaginar visões, projetar e estruturar organizações e dar vida a essas organizações. O know-how básico de gerenciamento também é útil: em acréscimo aos conteúdos do PODC (planejamento, organização, desenvolvimento e controle), poderiam ser incluídos: contabilidade, finanças, marketing, sistemas de informação, etc. É necessário cuidado, no entanto, porque muito freqüentemente programas de empreendedorismo e pequenos negócios assumem uma perspectiva gerencial, uma vez que é isso que os criadores desses programas estão acostumados a fazer. Eles têm familiaridade com isso. Em alguns casos, cursos de gerenciamento já existentes são incluídos em programas de empreendedorismo ou de pequenos negócios sem nenhum cuidado em adaptá-los para refletir o contexto do empreendedorismo ou dos pequenos negócios.

\section{$\mathrm{O}$ que os empreendedores fazem está intimamente ligado à maneira como interpretam o que está ocorrendo em um setor em particular do meio.}

Aqui, contingência é vital caso se espere que os participantes deixem o programa preparados adequadamente para serem bem-sucedidos em seu novo papel de empreendedores. Especialistas na área já mos- traram que programas de empreendedorismo devem ser diferentes de programas de gerenciamento (Gibb, 1987; Brown and Burnett, 1989; Kirby, 1989; Thorpe, 1990; Johannisson, 1991; Filion, 1992; Ulrich e Cole, 1992). Béchard e Toulouse (1993) chegaram a desenvolver um sofisticado sistema para classificar abordagens educacionais do empreendedorismo como tal. O Quadro 5 fornece algumas diretrizes para o desenvolvimento de programas e atividades de formação empreendedora.

Os detalhes do programa dependerão do nível educacional da instituição: primário, secundário, universitário, centros de empreendedorismo e serviços de treinamento para adultos sem pré-requisitos e que ofereçam cursos abertos. Nos níveis primário e secundário, os programas devem enfocar basicamente o autoconhecimento. A ênfase aqui é desenvolver a capacidade empreendedora $^{2}$ (Fortin, 1992), ou seja, preparar os alunos para criar seus próprios empregos lançando seus próprios negócios. No nível universitário, o foco deverá ser em ambos: autoconhecimento e know-how.

Considerando as necessidades de aprendizagem envolvidas - entender contextos e definir situações -, a

\section{Quadro 5 - Diretrizes para atividades do ensino do empreendedorismo}

\begin{tabular}{|c|c|}
\hline & $\begin{array}{l}\text { Cada curso deverá ser concebido de modo a permitir que cada participante identifique o que quer aprender e defina a } \\
\text { estrutura na qual vai aprender (Filion, 1989). }\end{array}$ \\
\hline • & Cada curso deverá incluir estratégias de multiinstrução. \\
\hline & Cada curso deverá ser concreto e prático. \\
\hline • & Cada curso deverá apresentar material que será útil na prática quando o curso estiver concluído. \\
\hline & $\begin{array}{l}\text { Cada curso deverá ser visto pelos participantes como uma atividade de aprendizagem, e não apenas como } \\
\text { transmissão de conhecimento pelo professor. }\end{array}$ \\
\hline & $\begin{array}{l}\text { Cada curso deverá incluir interação com empreendedores reais por meio de estudos de casos, vídeos e reuniões com } \\
\text { empreendedores em sala de aula e trabalhos de campo em que pelo menos um empreendedor seja estudado a fundo. }\end{array}$ \\
\hline & $\begin{array}{l}\text { Cada curso deverá incluir acompanhamento pessoal dos objetivos de aprendizagem de cada participante. A formação } \\
\text { empreendedora lembra a formação de liderança ao requerer um mínimo de acompanhamento individual. }\end{array}$ \\
\hline & $\begin{array}{l}\text { Os estudos de casos deverão ser adaptados às características da área. Eles deverão ajudar os participantes a } \\
\text { aprender a entender contextos e a definir situações. }\end{array}$ \\
\hline
\end{tabular}


experiência tende a mostrar que o autoconhecimento e o know-how empreendedores são mais bem ensinados com exercícios nos quais os estudantes definam contextos, trabalhem com base em testemunhos pessoais e em casos inspirados em entrevistas com empreendedores.

Mais de uma década de pesquisa sobre sistemas de atividade empreendedora e experiência em treinamento nessa área ensinou ao autor a importância de adaptar a educação empreendedora para refletir o que os empreendedores são e fazem. Isso implica consideráveis diferenças, por exemplo, no uso de casos na educação empreendedora em comparação à educação gerencial. Os objetivos educacionais são bem diversos. Em ambas as situações, para ser válido, o uso de casos deve refletir o contexto da disciplina em si e os tipos de autoconhecimento e know-how necessários para levar à frente aquilo que os estudantes estão sendo treinados para fazer. Empreendedores são sempre "diferentes", desempenhando, nos negócios, papéis distintos daqueles dos gerentes. Para eles, autoconhecimento significa identificação com modelos e entendimento sobre como desenvolver e expressar suas diferenças, enquanto, para os gerentes, significa adaptar- se aos contextos organizacionais e ajustar-se a eles. Empreendedores devem identificar oportunidades e conceber maneiras de explorá-las. Para os gerentes, know-how quer dizer utilizar ao máximo suas áreas de especialidade; para os empreendedores, quer dizer definir conceitos com base em elementos latentes. Empreendedores em potencial têm claramente muito a aprender ouvindo empreendedores experientes descreverem como foram bem-sucedidos imaginando algo novo.

\section{Os empreendedores não apenas definem situações, mas também imaginam visões sobre o que desejam alcançar.}

Tanto a criação quanto o uso do material educacional são importantes. Por exemplo, um caso poderá ser usado para ensinar os alunos a avaliar as potencialidades, as fraquezas e a coerência dos empreendedores estudados. Entretanto, pode ser igualmente interessante usar um caso para ensiná-los a de- finir contextos, fazendo com que criem questionários ou exercícios que os ajudem a desenvolver sua própria abordagem e estrutura de trabalho para entender e definir contextos. Podem, então, fazer um estudo comparativo de como o empreendedor fez isso e como eles próprios o fariam. Por exemplo, procurar elementos semelhantes na identificação de oportunidades é sempre estimulante. Definir as características de seu ambiente, ter uma visão e imaginar o tipo de empresa necessária para explorá-la e comparar tudo isso à maneira como um empreendedor real fez dá aos estudantes uma oportunidade de aprendizagem fascinante.

Estes últimos anos assistiram a uma proliferação de cursos básicos de empreendedorismo. Chegamos a um ponto em que é necessário fazer distinção entre as várias áreas do empreendedorismo e segmentar a educação empreendedora. O Quadro 6 sugere alguns caminhos para isso.

\section{CONCLUSÃO}

A experiência mostra que, ao nos tornarmos mais especializados em uma área de educação, tendemos a desenvolver material de ensino mais bem adaptado. A educação empreendedora deveria estar voltada para

\section{Quadro 6 - Diferentes áreas do empreendedorismo e da educação empreendedora}

\begin{tabular}{|l|l|l|}
\hline - Empreendedores & - Inovação, visão, crescimento, projeto \\
\hline - Auto-empregados e microempresas & - Orientação de mercado, ecologia pessoal, equilíbrio pessoal \\
\hline - Pequenos negócios & $\begin{array}{l}\text { Atividades gerenciais, tais como marketing, finanças, gerenciamento } \\
\text { de operações, gerenciamento de sistemas de informações } \\
\text { e de recursos humanos, em um contexto em que os recursos, } \\
\text { incluindo o tempo, são restritos }\end{array}$ \\
\hline - Empresas familiares & - Sociossistemas, instrumentalidade \\
\hline - Intrapreendedores ${ }^{3}$ & - Inovação, sistemas de suporte, manutenção de relacionamentos \\
\hline - Empreendedor de risco & $\begin{array}{l}\text { Avaliação de oportunidades, gerenciamento de riscos, processos } \\
\text { gerenciais complexos }\end{array}$ \\
\hline Tecnoempreendedor & $\begin{array}{l}\text { Trabalho em equipe, quasi-boards }{ }^{4}, \text { orientação de mercado, } \\
\text { redes de trabalho, globalização }\end{array}$ \\
\hline
\end{tabular}


a aprendizagem do autoconhecimento e do know-how, que permita ao futuro empreendedor uma estrutura de trabalho mental empreendedora. Num programa educacional, o que importa não é somente o que se ensina, mas também o padrão de aprendizado estabelecido com o processo de aprendizado envolvido. No caso de estudantes de empreendedo- rismo, o padrão de aprendizagem adquirido deveria inspirá-los a buscar um aprendizado contínuo e deixá-los mais à vontade com o novo papel empreendedor que estarão desempenhando. Uma vez que tenham adquirido essa base, por si só irão definir o know-how gerencial que precisam aprender caso estejam para realizar alguma visão. $\bigcirc$
Louis Jacques Filion é Mestre em Relações Internacionais pela Universidade de Ottawa, MBA pela HEC (the University of Montreal Business School), Ph.D. em Entrepreneurship pela Universidade de Lancaster e Professor responsável pela cadeira de Entrepreneurship MacLean Hunter da HEC.

E-mail: louisjacques.filion@hec.ca

Revisor da tradução: Fernando Dolabela, Professor de Empreendedorismo do

Programa REUNE, CNI-IEL Nacional. E-mail: dolabela@fumsoft.softex.br

\section{REFERÊNCIAS BIBLIOGRÁFICAS}

ARCHAMBAULT, G. Le perfectionnement des manages: au-delà des modes et des engouements. Gestion, p. 6-15, May 1992.

BÉCHARD, J. P., TOULOUSE, J. M. Entrepreneurship training: a look from educational sciences. Montréal, Mar. 1993. MacLean Hunter Entrepreneurship Chair Working Paper n. 93-03-01.

BOYATZIS, R. E. The competent manager. a model for effective performance. Wiley, 1982.

BROCKHAUS, R. H. Sr., HORWITZ, P. S. The psychology of the entrepreneur. In: SEXTON, D. L., SMLLOR, R.W. (Eds.). The art and science of entrepreneurship. Ballinger, 1986.

BROWN, R., BURNETT, A. Enterprising Graduates and the English Graduate Enterprise Program, 1985-1989. In: NATIONAL UNITED KINGDOM SMALL FIRMS POLICY AND RESEARCH CONFERENCE, 12., 1989, London.

CHRISTENSEN, C. R. Teaching and the case method. Cambridge (MA) : Harvard Business School, 1992.

DRUCKER, P. F. Innovation and entrepreneurship. New York : Heinemann, 1985.

ERSKINE, J. A., LEENDERS, M. R., MAUFFETTELEENDERS, L. A. Teaching with cases. Ontario University of Western Ontario, 1981.

FILION, L. J. The strategy of successful entrepreneurs in small business: vision relationships and anticipatory learning. Thesis (Ph.D.) - University of Lancaster, Great Britain, 1988 (UMI 8919064).

FILION, L. J. The design of your entrepreneurial learning system: identify a vision and assess your relations system. In: CANADIAN CONFERENCE ON ENTREPRENEURIAL STUDIES, 3., Sept. 1989, Calgary. Proceedings... Calgary : McKIRY, J. G. M., 1989. p. $77-90$
FILION, L. J. Vision and relations: elements for an entrepreneurial metamodel. In: ANNUAL BABSON ENTREPRENEURSHIP RESEARCH CONFERENCE, 10., Apr. 1990, Babson College, MA. In: CHURCHILL, N. C. etal. (Eds.). Frontiers of entrepreneurship research 1990 Proceedings of the Tenth Annual Babson College Entrepreneurship Research Conference. Babson, 1990. p. $57-71$.

FILION, L. J. Vision et relations: clefs du succés de l'entrepreneur. Montréal :Éditions de l'entrepreneur, 1991.

FLLION, L. J. Ten steps to entrepreneurial teaching. In: NEDI (NATIONAL ENTREPRENEURSHIP DEVELOPMENT INSTITUTE) NATIONAL CONFERENCE ON ENTREPRENEURSHIP EDUCATION, 2., June 1992, Moncton (Canada).

FORTIN, P. A. Devenez entrepreneur. Québec : Éditions de l'entrepreneur, 1992.

GASSE, Y. Prospectives d'une éducation entrepreneuriale: vers un nouveau partenariat éducationorganisation. In: ANNUAL CONFERENCE, CANADIAN COUNCIL FOR SMALL BUSINESS AND ENTREPRENEURSHIP, 9., Oct. 1992, Victoria (Canada).

GIBB, A. A. Enterprise culture: its meaning and implications for education and training. Journal of European Industrial Training, v. 11, n. 2, p. 3-38, 1987.

HILL, L. A. Becoming a manager. mastery of a new identity. Cambridge (MA) : Harvard Business School, 1992.

HISRICH, R. D. The woman entrepreneur: characteristics, skills, problems and prescriptions for success. In: SEXTON, D. L., SMILOR, R. W. (Eds.). The art and science of entrepreneurship. Ballinger, 1986. p. 61-81.

HORNADAY, J. A. Research about living entrepreneurs. In: KENT, C. A. et al. (Eds.). Encyclopedia of entrepreneurship, Englewood Cliffs : Prentice-Hall, 1982. p. 20-34.
JOHANNISSON, J. A. University training for entrepreneurship: Wedish approaches. Entrepreneurship and Regional Development, v. 3, n. 1, p. 67-82, 1991.

KIRBY, D. A. Encouraging the enterprising undergraduate. Education and Training, v. 31, n. 4, p. 9-10, 1989.

KOTTER, J. P. The general managers. Cambridge (MA) : Harvard Business School, 1982.

LAWRENCE, P. R., LORSCH, J. W. Organization and environment: managing differentiation and integration. Cambridge (MA) : Harvard University Press, 1967.

MINTZBERG,H. Themanager'sjob: folkloreandfacts. Harvard Business Review, v. 53, n. 4, p. 49-61, July/Aug. 1975.

PETERSON, R. A. Entrepreneurship and organization. In: NYSTROM, P. C., STARBUCK, W. H. (Eds.). Handbook of organization design. Oxford: Oxford University Press, 1981. v.1.

RONSTADT, R. The art of case analysis. Dover : Lord Publishing, 1977.

THORPE, R. Alternative theory of management education. Journal of European Industrial Training, v. 14, n. 2, p. 3-15, 1990

TIMMONS, J. A. Characteristics and role demands of entrepreneurship. American Journal of Small Business, v. 3, n. 1, p. 5-17, 1978.

ULRICH, T. A., COLE, G. S. Industrial strategies for entrepreneurship education. In: ICSB WORLD CONFERENCE, 37., June 1992. Proceedings... ICSB, 1992. p. 586-605.

WORTMAN, M. S., BIRKENHOLZ, W. Entrepreneurship research on a global basis: an empirical based model. In: ICSB WORLD CONFERENCE, 36., June 1991, Vienna. Proceedings... Vienna : ICSB, 1991. v. 1, p. 67-77.

\section{NOTAS DO REVISOR}

1. Do inglês self-awareness.

2. Do inglês entrepreneuriability.
3. Do inglês intrapreneur.

4. Do inglês quasi-boards, que é uma espécie de con- sultoria dada por uma "diretoria virtual", composta de profissionais experientes, externos à empresa. 